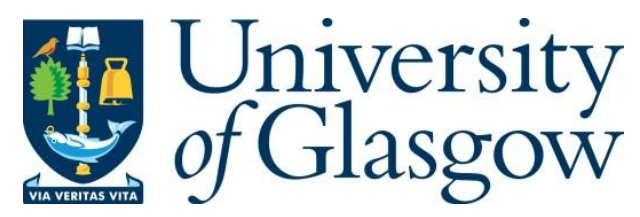

Patent, V. and Searle, R. H. (2019) Qualitative meta-analysis of propensity to trust measurement. Journal of Trust Research, 9(2), pp. 136-163.

There may be differences between this version and the published version. You are advised to consult the publisher's version if you wish to cite from it.

http://eprints.gla.ac.uk/202253/

Deposited on: 21 May 2020

Enlighten - Research publications by members of the University of Glasgow http://eprints.gla.ac.uk 


\section{Qualitative Meta-analysis of Propensity to trust measurement}

Volker Patent ${ }^{\mathrm{a} *}$ and R. Searle ${ }^{\mathrm{b}}$

${ }^{a}$ School of Psychology, Faculty of Arts and Social Sciences, The Open University, Milton Keynes, United Kingdom;

${ }^{b}$ Adam Smith Business School, University of Glasgow, Glasgow, United Kingdom email for*corresponding author: volker.patent@open.ac.uk 


\section{Qualitative Meta-analysis of Propensity to trust measurement}

In a rapidly changing and dynamic world, individuals' propensity to trust is likely to become an increasingly important facet for understanding human behaviour, yet its measurement has mostly been unexplored. We undertake the first systematic qualitative survey of propensity to trust scales using qualitative meta-analysis methodology to review the literature (1966 - 2018) and identify 26 measures and their applications in 179 studies. Using content analysis, we show and discuss how these scales are thematically organised into six thematic areas. We find that while most of these scales reflect propensity to trust in terms of a positive belief in human nature, other themes include general trust, role expectations, institutional trust, cautiousness and other personality attributes. We reveal significant methodological concerns regarding several scales, and argue for more considered selection of scales for use in research. We examine the case for multidimensionality in measures propensity to trust used within organisational context research. Rather than treating a lack of generalisability of findings in existing organisational studies as purely a problem of measurement design, we instead outline an agenda for further conceptual and empirical study.

Keywords: trust; disposition; review; qualitative meta-analysis; trust dimensions 


\section{Introduction}

Why do some people trust more readily than others? The escalating dynamism for organisations coupled with wide-ranging impacts of change for modern workers, make it increasingly important to understand individual difference dimension to trust (Frazier, Johnson, \& Fainshmidt, 2013; McKnight, Cummings, \& Chervany, 1998). Indeed, extant research reveals disposition to trust as more influential within organisational contexts at critical stages in individuals' relationships with others, such as at the start of new and unfamiliar relationships (McKnight et al., 1998), during organisational entry (Klotz, Motta Veiga, Buckley, \& Gavin, 2013; Searle \& Billsberry, 2011), or in settings requiring rapid establishment of cooperative practices (e.g., virtual teams: Jarvenpaa, Knoll, \& Leidner, 1998). Further, dispositional aspects of trust can be of value in understanding intra-group relations, shedding light on the unintended and detrimental consequences of breakdowns in trust for organisational dynamics (Ferguson \& Peterson, 2015). Despite such clear significance, there has been a surprising lack of attention to understand why and how some individuals trust more readily than others (Colquitt, Scott, \& LePine, 2007; Dietz, 2011).

Trust is commonly defined as a confident expectation about a situation leading to willingness to accept vulnerabilities that arise from situational uncertainty and risk (Dietz, 2011). Such expectations have dispositional antecedents which influence other process dimensions (Dietz \& Den Hartog, 2006; Mayer, Davis, \& Schoorman, 1995). The idea of trust as a dispositional construct is usually attributed to Rotter (1967), who used the term 'generalised trust' to describe the tendency to believe that others can generally be trusted. Disposition to trust is defined as 'the extent to which one displays a consistent tendency to be willing to depend on others in general across a broad spectrum of situations and persons ${ }^{6}$ (McKnight \& Chervany, 2001, p. 45). While there are a variety of terms used to describe this 
concept, more recently it has become referred to as 'propensity to trust' (P2T). Currently, P2T provides the dominant individual-based conceptualisation as to why some people trust others more readily (Dietz \& Den Hartog, 2006; Mayer et al., 1995).

While P2T has been considered highly relevant to research into trust in organisations, there has been little critical interrogation of the quality of a growing body of the scales used to measure this construct. Indeed, several authors have expressed concern about the lack of reliable measures, to support their development of new measures (Ashleigh, Higgs, \& Dulewicz, 2012; Frazier et al., 2013; Schoorman, Mayer, \& Davis, 2007). In the absence of focused reviews on P2T measurement, the aims of this paper are: 1. to provide a synoptic examination of currently used P2T scales and qualitatively map their construct space using qualitative meta-analysis; 2 . to identify the conceptual and methodological implications of the different facets present within these scales; and 3. to outline the implication for the development of trust research, making recommendations to improve the quality of scales used in research. To achieve these aims, our paper critically evaluates the topic of P2T measurement, examining the content of P2T measures, their characteristics and use in trust research. Through this process we make three contributions: First, a comprehensive review of published P2T measures within the literature (1966-2018); Second, examination of the conceptual and methodological assumptions underpinning P2T measurement, focussing on scale characteristics, their content, validation, and applications; Finally, identification and discussion of the empirical and conceptual implications relating to organisational and management research, including an agenda to advance the field.

Our paper commences with a short review of the conceptual origins and definitions of $\mathrm{P} 2 \mathrm{~T}$ and the methodological context of $\mathrm{P} 2 \mathrm{~T}$ as situated within trust research, providing a rationale for our qualitative meta-analysis of scales for this construct. Finally, the findings and implications of our meta-analytic survey are discussed in light of research and theory. 


\section{Theoretical origins and conceptual definitions}

P2T originated in psychology in the 1950s, when the idea developed that trusting others is driven by aspects of personality and beliefs. For example, Erikson (1950) viewed an adult's ability to trust as dependent on the resolution of the earliest formative developmental stage (basic trust versus basic mistrust), which provides the foundation for a healthy personality system. From this perspective, trust is synonymous with confidence, the absence of which produces anxiety and has clear origins in the childhood development of personality.

Early personality theorists interested in trust departed from therapeutic notions and developmental assumptions about trust to adopt a more modern psychological conceptualisation. For example, Rotter (1967) defined a person's capacity for trust as based on '.. an expectancy held by an individual or a group that the word or promise, verbal or written statement of another individual or group can be relied upon' (p. 651). Similarly, Wrightsman (1964) was interested in attitudes about other people's behaviour as part of a system of beliefs about human nature, defining trust attitudes as ' ...the extent to which people are seen as honest, moral and reliable.' (p. 744). There have since been a variety of other definitions (see Table 1).

\section{[Table 1 near here]}

Mayer et al. (1995) defined P2T as a general willingness to trust. Others, for example, Connell and colleagues paraphrased Kramer (1999) to describe propensity to trust as 'an individual's inclination to believe that others will be prepared to act in the trustor's best interests' (Connell, Ferres, \& Travaglione, 2003, p. 570). Chen \& Barnes (2007) summarise a variety of conceptions of P2T as follows: 'a general tendency or inclination in which people show faith or belief in humanity and adopt a trusting stance toward others' (p. 24). As a general tendency P2T is conceptually distinct from particularised trust, which is the 
propensity to place high trust in relationships that are closely tied and familiar, and feature in day-to-day interactions (Uslaner, 2002), rather than more generalised.

Definitions of P2T differ in their implicit theoretical assumptions and emphases, for example, P2T origins (genetic, trait, beliefs) and the extent to which P2T is dependent on, and an expression of: context, social exchange, and social relationships. These disparities reflect researchers' different theoretical and thematic preoccupations. However, they also reveal a source for definitional confusion in the absence of a unified theoretical and conceptual definition, which has also contributed to the systemic definitional problems which have effected trust research since its inception.

To some extent, definitions of $\mathrm{P} 2 \mathrm{~T}$ align with two of the three requirements for trust. The first requirement, dependence, arises from the tendency in social exchange for trust to be reciprocal in which both trustor and trustees have relative degrees of dependency on each other (Blau, 1964). The second requirement, vulnerability (Rousseau, Sitkin, Burt, \& Camerer, 1998) arises from the potential impact of losses that can result from said dependency between the trustor and trustee. In most instances, this is generally implied rather than being made definitionally explicit. Finally, uncertainty (Lewis \& Weigert, 1985), appears not to be captured in definitions of P2T. This omission is noteworthy because a general tendency to rely on others only makes sense if reliance occurs in the presence of both losses and outcome uncertainty, which together produce risk (Yates \& Stone, 1992). None of the shorter definitions we found included uncertainty, although it was often mentioned in the more detailed accounts of trust in which P2T is being contextualised (see, for example, Colquitt et al., 2007; Mayer et al., 1995; McKnight \& Chervany, 2001). One possibility is that the concept of risk is often presumed to include uncertainty, but potentially then it confounds the harm caused by risk with its probability or chance (Ale, 2009; Yates \& Stone, 1992) which is why we draw attention to its separation. 
Depending on the focus applied, $\mathrm{P} 2 \mathrm{~T}$ is concerned with a general readiness for accepting vulnerability, based on general beliefs about people and trust situations (Stack, 1978), that precede people's judgements of other people's trustworthiness and their specific expectations about a situation (Mayer et al., 1995). While there are specific aspects to any trust situation, often these are not known at the beginning of a relationship. In the absence of such information P2T serves to provide individuals with a basis for coping with a situation, even when they have little or no prior experience of that setting or the people within it (cf. Rotter, 1980, p. 2).

When positioned as an aspect of personality, P2T has been considered as a stable characteristic, rather than situation-specific (Mayer et al., 1995). The predominant view is that P2T acts as a unidimensional personality trait which influences a person's general willingness to trust and take risks (Farris, Senner, \& Butterfield, 1973; Gillespie, 2003), although this is not universally accepted (Ashleigh et al., 2012). Evans \& Revelle (2008) report evidence that trust is associated with extraversion, neuroticism, agreeableness and conscientiousness, suggesting a slightly more complex view of P2T and trait theory that draws raises the possibility that $\mathrm{P} 2 \mathrm{~T}$ may comprise multiple dimensions which reflect underlying personality traits. A further conceptual distinction between traits and states leads one to consider whether a willingness to render oneself vulnerable reflects a variable state (Boon \& Holmes, 1991; Das \& Teng, 2001; Jones \& George, 1998) within the traits activated in a given situation.

There is consistent support for Mayer et al.'s (1995) idea that P2T operates as an antecedent in trust situations, generating trustworthiness perceptions (Colquitt et al., 2007; Gill, Boies, Finegan, \& McNally, 2005). Furthermore, P2T appears to act directly and independently of trustworthiness information on trust outcomes analogous to an information filter (Govier, 1994; Searle, Weibel, \& Den Hartog, 2011); thus those higher in P2T filter out 
negative, counter-indicative information and thereby become more resilient to breaches in trust. This filtering explains why some individuals seem to be less affected by unfavourable trustee cues, less likely to become sceptical, regardless of the amount of contrary information, and therefore can make the cognitive leap required for trust based on little else than their general tendency to trust (Searle et al., 2011).

In summary, defining P2T is difficult, as it has similarly slippery tendencies as definitions of trust (Nooteboom, 2000). In practice, the definitions used in research may well reflect differences in emphasis rather than fundamental distinctions in articulating P2T within theoretical models. While noting these definitional variations, our review of conceptual definitions and ideas concerning its role in social exchange adopts the following broad conceptual definition for P2T: A more or less stable tendency to rely on others, expecting them to be generally trustworthy and reliable unless proven otherwise, independent of person, context or lifetime.

\section{Is the measurement of P2T flawed?}

A variety of measures are associated with P2T, although to our knowledge there has been no systematic review of their quality or application, nor the extent to which they actually assess the construct described in the previous section.

Gillespie's (2012) work on the measurement of trust notes that trust research is often reliant on flawed, and poorly validated instruments. She attributes this to several causes: (1) fragmented and idiosyncratic use of measures resulting from the proliferation of new measures including those developed from earlier measures; (2) lack of evidence to support construct validity; (3) and misalignment between conceptualisation and measurement.

Flawed measurement is an argument that has also been made for P2T, although not as strongly as for trust measures. Schoorman et al. (2007) called for the development of better 
P2T measures following an evaluation of two measures, Schoorman, Mayer, and Davis (1996) and Rotter ( 1967), which they argue have poor psychometric characteristics.

However, systematic review shows more than two scales in operation (our review highlights 26, most of which were available in 2007). As a result, attention towards devising new measurement tools may have failed to capitalise on the strengths of existing psychometrically robust measures. A further unintended consequence of new scale calls is fragmentation, making comparison across studies using different measures difficult. Furthermore, the creation of new scales often involves use of legacy scale items inadvertently duplicating existing flaws. Thus, rather than solving a measurement problem, new P2T scales may proliferate existing problems that have already marred measurement in trust research in general (McEvily \& Tortoriello, 2011).

Further scrutiny of measures reveals a misalignment between P2T's conceptualisation and its subsequent operationalisation in research. Problems with alignment appear most acute in trust studies of institutional contexts (Li, 2013). Without attention to unresolved construct validation, conceptual and conceptual alignment limitations of established scales are merely replicated. Therefore, while concerns about measurement quality have been noted, in contrast with measures of organisational trust (see for example Dietz and Den Hartog, 2006), to date no comprehensive investigation has been undertaken of the underlying scale content and quality of P2T scales. To provide such critical insight and to extend conceptual work on trust measurement, this paper systematically surveys individual P2T scales used in contemporary trust research. 


\section{Method}

\section{Qualitative meta-analysis of P2T scales}

The methodologies used to identify and evaluate P2T scales and their items in this paper were derived from qualitative meta-analysis. This approach emerged in qualitative social sciences as a means of summating qualitative findings (Timulak, 2013). However, it has also been shown to have application in the thematic analysis of research in fields usually dominated by quantitative approaches (Nienaber, Romeike, Searle, \& Schewe, 2015). Such work suggests that the technique is adaptable to situations when a more thematic summarisation (in this case a summary of the scales used in the literature) is required. Indeed quantitative and qualitative meta-analyses often ask similar research questions but rather than following a cookbook approach, qualitative researchers adapt the methodology, depending on a study's research goals (Levitt, 2018). In this paper, the thematic summarisation focuses on P2T scales used in different studies, and so the term meta-analysis concerns the identification of scales and their characteristics, as well as gaining insight about their applications in research.

Our use of qualitative meta-analysis also draws on the meta-inventory approach used by Cheng and Fleischmann (2010) in their qualitative mapping and development of a metainventory of human values measures. Furthermore, pragmatically our methodology builds on the seminal analysis of trust measuremenet by Dietz and Den Hartog (2006) and their mapping of organisational trust measurement, extending this approach to map P2T. Our methodology is therefore thematic and descriptive, rather than quantitative and directed by statistical decision-making. While we recognise that P2T scales and their use are embedded within a quantitative paradigm of research methodologies, our adoption of qualitative methodologies promises fresh insights that are less likely to emerge from a more quantitative, positivist analysis. Our intent is not to dismiss quantitative approaches in trust research, but 
rather to extend them using qualitative methods and epistemologies as suggested by others (Isaeva, Bachmann, Bristow, \& Saunders, 2015).

In assessing the quality of qualitative research, reliability and validity are conceptualised differently, and therefore, differ in their application compared with quantitative work (Morse, Barrett, Mayan, Olson, \& Spiers, 2002). Axiological considerations drove the emergence of data and insights gained in this study as a step in a larger research project on P2T. It is for this reason that we are less concerned with a traditional psychometric discussion of scales' validity and reliability and instead, we are more concerned with reporting the development of our sense-making about P2T measures; these encompass the concepts of fidelity and utility, against which to judge methodological integrity in qualitative meta-analysis (Levitt, 2018). For this reason, we have included a final coding of the items and list of studies collected (Appendices $1 \& 2$ ) to be transparent in the outputs of our methods. While we adopt a somewhat more constructivist stance epistemologically, in this context, some discussion of psychometrics is inevitable. In addition to our treatment of quantitative technical issues in the discussion, we used inter-rater reliability analysis to guide and verify the revision of our qualitative coding frames.

\section{Data collection \& Methodology}

Following qualitative meta-analysis methodologies employed by others (Nienaber et al., 2015; Oreg, Vakola, \& Armenakis, 2011) we first carried out an extensive search for P2T scales and studies that have used them. Searches were performed using search engines including Web of Science (ISI), EBSCOhost and Google Scholar involving well-known scale names (e.g., 'faith in people scale' \& 'interpersonal trust scale'). As inconsistent terminology has been used to denote P2T (e.g., dispositional trust, general trust), scale identification was made more problematic with searches failing to discriminate between studies using a measurement tool and those discussing the concept, or merely mentioning a scale. Therefore, 
to identify comprehensively those studies that had used any of the scales, we deployed snowballing and reverse snowballing (Sayers, 2008) to narrow searches including the use of items from published scales as search terms.

Guided by our conceptual definition of P2T, we focused only on scales whose content and operationalisation claimed to measure 'a tendency to be trusting' or 'believing that, in general, others could be trusted'. Because we were interested in the organisational context applications of scales, we restricted the scope of our meta-analytic review to studies with some relevance to the fields of management, leadership, organisational behaviour, marketing and online trust. Although much of the marketing online trust literature deals with trust in online services, it has relevance to organisations since typically it relates to reputation, word of mouth and other behavioural intentions. These elements are pertinent to organisational recruitment and selection processes, as well as to inter- and intraorganisational trust, which is increasingly reliant on online digital media and communication. Finally, in some cases, we allowed inclusion of studies that had an educational or health focus, or which embodied more general or social psychological topics (for example person perception, emotion regulation, economic psychology) if they had relevant applicability to behaviour in organisations and used one of the identified P2T scales.

We excluded hybrid scales which adapted items from existing instruments such as items from Rotter's (1967) interpersonal trust scale or the P2T scale developed by Schoorman et al. (1996). While the latter uses items from Rotter's scale, the popularity of their scale demanded its inclusion in our review. Also included was Valenzuela, Park, and Kee's (2008) adapted version of Rosenberg's (1956) scale for administration in Likert scale format. We excluded scales that measured particularised general trust in institutions (e.g., Kehr, Kowatsch, Wentzel, \& Fleisch, 2015) or towards particular actors, such as trust in medics (e.g., Hall, Camacho, Dugan, \& Balkrishnan, 2002). 
Next, we carried out content analysis. Items from the identified scales were extracted and coded by both authors to capture their thematic content. An initial coding frame was derived from dimensions and discussions found in the trust and P2T literature. We built on Hsieh \& Shannon's (2005) approach complemented by a broader, and arguably more subjective thematic content analysis (Neuendorf, 2016). This thematic orientation allowed themes to emerge from the wording of scale items, while also being directed by literaturederived theoretical constructs. Initial low inter-rater reliability led to category discussion and a decision to collapse several of the categories together. Inter-rater reliability of the initial and final coding frames used Kappa analysis (Cohen's $\kappa)$. In the final reporting, the resultant themes were organised following McKnight, Choudhury, and Kacmar's (2002) scale content tabulation approach.

\section{Results}

The extensive literature search identified 179 relevant studies, comprising 26 P2T scales (see Table 2; a list of references is provided in Appendix 2).

[Table 2 near here]

The original scale validation studies and most studies report reliabilities. However, some original validation studies did not report reliability, so a composite average was calculated from reported reliabilities. Average reported alpha reliability across all scales and studies was .78 , ranging from .40 to .97 .

In contrast with the assertion of Schoorman et al. (2007) that no unidimensional P2T measures produce consistently high alphas, twelve of the twenty-six measures revealed average reliabilities above .80 (The reliability coefficients and other pertinent characteristics of each of the scales are elaborated further below in table 5 and in the discussion). In several of the validation studies of P2T scales, factor analysis was reported, rather than criterionrelated validation. The scales varied widely in their approach to and depth of the validation 
strategy, with several using factor analysis, and only more recent validations extending beyond simple principal components analysis (e.g., McKnight et al., 2002).

Almost all the studies identified in our meta-analytic literature review used a conceptual definition of $\mathrm{P} 2 \mathrm{~T}$ as either a generalised/general tendency to trust, or as dispositional trust to justify the use of specific scales. Those studies referring to the origins of P2T measures mostly attributed the concept to Rotter (1967), or, occasionally, depending on the scale, to Schoorman et al. (1995). More detailed examination of their application reveals that different fields of study favour different scales. For example, consumer and online trust applications almost exclusively use several scales (e.g., Gefen, 2000; Lee \& Turban, 2001; McKnight et al., 2002; Valenzuela et al., 2008) that are rarely found in organisational and managerial study of trust.

In our sample of studies, P2T measures were commonly used as predictor variables of social or organisational processes/behaviour (e.g., Gill et al., 2005), or as moderators in the relationship between two or more variables (e.g., Hansen, Dunford, Alge, \& Jackson, 2015). Over the last two decades, there has been an increasing inclusion of P2T within structural equation models (e.g., Frazier, Gooty, Little, \& Nelson, 2015; Ridings, Gefen, \& Arinze, $2002 ; 13 \%$ of our studies). Within experimental designs, P2T has commonly been used as a control variable (e.g., Norheim-Hansen, 2015; 10\% of studies in our sample).

\section{Analysis of scale content}

Thematic content analysis of the items produced an initial twelve themes, which reduced further to a final six key themes (see Table 3).

[Table 3 near here]

Items categorised HN ('faith in human nature') reflected beliefs in people's honesty, sincerity, fairness, reciprocity, cooperativeness and competence as a basis for a general faith 
in human nature. 'Cautiousness' (C) items expressed reasons to be cautious and concern about risks and exploitation. 'Role expectations'(RE) referred to specific trustee categories (e.g., salespeople, experts, politicians, students, parents) and the degree to which they could, in general, be trusted. 'Institutional trust' (I) was similar to RE but concerned a general tendency to trust organisations as the trustee (e.g., companies, media and political institutions), rather than individuals. 'Personality attributes' (P) comprised those items expressing self-reported personality characteristics not featured in other categories, and statements reflecting a general optimistic tendency. Finally, 'general trust' $(\mathrm{G})$ captured items which expressed a self-reported tendency to trust without further reference to other qualifiers.

Cohen's $\kappa$ was calculated for a $20 \%$ random sample of scale items to assess the quality of the coding frame. The primary author and a second coder, who was an independent researcher with experience of trust research, carried out this coding. Both rated items independently using the same six-factor coding frame. The inter-rater reliability was Kappa = $.83(\mathrm{p}<.0 .001), 95 \% \mathrm{CI}(.0 .720,0.0 .939)$ indicating substantial to almost perfect rater agreement (Landis \& Koch, 1977). A list of all scales, their items, and final codes is provided in Appendix 1.

Frequency tallies were used to indicate how often a given code occurred in each scale. These frequencies were then converted into a scale percentage to indicate thematic coverage levels for each scale (See Table 4).

[Table 4 near here]

Faith in human nature $(\mathrm{HN})$ was the dominant $\mathrm{P} 2 \mathrm{~T}$ item category, occurring in almost all scales, followed by 'cautiousness' (C) and 'general trust' (G). Themes were unevenly distributed across scales, with some scales featuring items belonging to only one or two themes. The number of themes was in part a function of the number of items, as those with 
more items often included more themes. None of the scales had complete thematic coverage; only two included five themes. $35 \%$ of scales only contained a single theme, most frequently G, (3 scales), followed by HN (2 scales) and RE ( 2 scales). The remaining two single theme scales covered $\mathrm{P}$ and $\mathrm{C}$, respectively. A further $30 \%$ of scales (8 scales) included two themes, $\mathrm{HN}$ and then either $\mathrm{C}, \mathrm{P}, \mathrm{G}$ or RE in that order of frequncies. The remaining nine scales included multiple themes (up to five). Each of these (except one) covered a human nature theme. I appeared in both of the five item scales and in one of the three item scales.

\section{Discussion}

The synoptic exploration of currently used P2T scales and qualitative mapping of the content provides insight into both conceptual and methodological limitations for the coverage of the different facets within P2T scales. To aid further discussion, we devised a table summarising the key attributes of individual scales (see Table 5).

[Table 5 near here]

\section{Fit of themes with the conceptual definition}

Referring to our conceptual definition, we expected somewhat different themes to emerge. First, the idea that P2T refers to expectations of others as generally trustworthy and reliable is met to a great extent, specifically via the $\mathrm{HN}$ and $\mathrm{G}$, and $\mathrm{P}$ themes. Our themes did not reflect the conceptualisation of 'unless proven otherwise'. Only a few scales refer to this idea (e.g., Rotter, 1967; Gefen, 2000).

The presence of RE and I themes is a little more troubling for the notion that expectations are independent of person, context or lifetime. Inclusion of items that tap role expectations or institutions seems to indicate that context or roles matter in people's tendency to be trusting, rather than being independent of them. While a qualitative analysis does not make as many assumptions about what themes should or should not be contained in a scale, 
there is a conceptual question about what the items labelled RE and I assess, and whether they should be included in scales. To that end, items falling into the RE and I themes are problematic because they can violate the idea of P2T being a general tendency (in the case of $\mathrm{RE}$ ), and are about reliance on others rather than aggregates (in the case of I). Alternatively, items falling under the RE headings are phrased to refer to general categories (e.g., salespeople, parents) rather than specific and particularised others (your parents, this salesperson). Even so, there may be a more fundamental issue about the relevance of such items to the contexts in which scales are applied, and the potential lack of face validity (for example items referring to students cheating at an exam, in research on team trust).

Considering further the question of 'what' P2T is (e.g. the expression of dispositional traits), it also becomes conceptually more difficult to distinguish between a direct expression of that trait, as a state, and the extent to which such judgements about trustworthiness of others are reflections of a) personal experience or b) normative beliefs about others that change over time or situations. For example, historically, trust in experts has been much higher than it is now. Public awareness of agenda-driven research (e.g. smoking, climate change), scientific fraud, and politicisation of expertise may have provided reasons for people to become generally more sceptical of experts than they were in the past (Pechar, Bernauer \& Mayer, 2018). The point here is that inclusion of items that are subject to cultural or historical change are unlikely to provide stable measurement of P2T, and thus changes in recorded P2T are more variable over time.

Finally, the emergence of the caution theme, which reflected mostly negatively worded items, does not neatly fit with any conceptualisation of P2T. However, considering the requirements for trust, vulnerability and uncertainty, the presence of items that tap a person's willingness to accept them would seem to be reasonable. There will be further discussion regarding dimensionality and negatively worded items below. However, rather 
than merely representing a potential weakness in the conceptualisation of $\mathrm{P} 2 \mathrm{~T}$ as such, we consider this emergent issue as supportive of the need to question how complete current conceptualisations of P2T are, with the view of improving future theory and research.

\section{The case for Multiple P2T dimensions}

Typically, P2T measures have been designed and operationalised as unidimensional scales. However, our thematic analysis has revealed coverage of multiple themes that raise the question to what extent P2T measures reflect a multidimensional construct. While only some scales were designed under the assumption of multiple subscales that are theoretically meaningful (e.g., Ashleigh et al., 2012; McKnight et al., 2002), other measures - although operationalised as unidimensional constructs - show multidimensionality emerging after initial scale validation. For example, factor analytic investigations of Rotter's (1967) unidimensional interpersonal trust scale reveal between two to four distinct dimensions (Hunt, Kohn, \& Mallozzi, 1983; Wright \& Tedeschi, 1975). Typically these dimensions contrast positive trust with a distrust/cautiousness factor and include less statistically robust factors of institutional trust, role expectations, and judgments of how reliable others are expected to be (Ashleigh et al., 2012; Hunt et al., 1983). Consistent with the arguments we made earlier regarding the conceptual fit of themes, scales which are assumed to be unidimensional may provide a conceptually incomplete view of P2T.

The distinction between trust and distrust in some scales aligns with the more recent consensus emerging around separate states of trust and distrust, rather than being mere opposites on a trust continuum (Saunders, Dietz, \& Thornhill, 2014). Only three scales explicitly operationalise both trust and distrust items in their original versions (e.g., Ashleigh et al., 2012; Huff \& Kelley, 2003; Yamagishi et al., 1999). While the scale developed by Schoorman et al. (1996) was initially developed as a unidimensional measure, subsequent factor analysis reveals separate trust and distrust dimensions (Murphy, 2003). Similarly, the 
unidimensional measure developed by MacDonald et al. (1972) shows distinctions between those who more readily endorsed trust compared to distrust, revealing men as more distrusting than women (Lagace \& Rhoads, 1988). This difference in participant groups' responses to items measuring distrust and trust highlights the importance of checking dimensionality within existing unidimensional scales of P2T.

The presence of a role expectations factor (RE) in factor analytic work supports our attention to the conceptual issues discussed in the light of our thematic analysis earlier. If P2T refers to trusting in general, the inclusion of specific categories of trustees (e.g., parents, teachers, students) potentially confounds single-score assessment of P2T with that of particularised trust. Particularised trust acts differently to P2T, for example, in the formation of strong group identity (Uslaner, 2002) and confounding P2T and particularised trust has important implications for interpreting results from studies that use P2T measures that include RE items but are operationalised as unidimensional.

Items coded as role expectations could also be interpreted as related to institutional trust (I). However, while qualitative analysis could comprise a coding frame in which RE is subsumed within I, there are several arguments against collapsing these two themes: First, people may be relying on role stereotypes based on social cues performed by role incumbents, for example, nurses being warm and friendly (Kong, 2018). Second, is the sharp contrast between trust in roles and institutions, for example, trusting medical doctors versus hospitals (Oliver, 2018). Third, not all the examples of RE concern professionals, with some items referring to trusting parents and students. Therefore an RE dimension would still be required. Evidence from factor analysis of some scales suggests that institutional trust is a separate factor distinct to RE, supporting our thematic analysis. Finally, understanding how trust operates at different levels is an increasingly important focus for study (Gillespie, Fulmer, \& Lewicki, forthcoming). Therefore the separation of referents by levels, such as 
individual role incumbents from their overarching institutional entities, may be advantageous to understand better how trust can operate at these different levels (Fulmer \& Gelfand, 2012). However, this requires careful attention to how measures (in this case, P2T) are operationalised to avoid losing information that may contribute to understanding individuals' tendencies to trust these different referents.

While we did not find any clear examples of this from our searches, unidimensional measures of P2T that include RE items may potentially result in spurious correlations between such P2T measures and some other variables depending on the context for trust. By separating dimensions in the analysis or removing such questions altogether, these conceptual considerations can be better monitored and controlled. Therefore, evaluating past studies that have used these scales should be undertaken with care to avoid over-interpretation of confounded unidimensional scale scores.

Another possible interpretation of the thematic dimensions found in our content analysis relates to nomological nets. Nomological nets here refers to the representation of the relationship between constructs by which construct validity might be inferred (Cronbach \& Meehl, 1955). P2T scores of presumed unidimensional constructs are potentially dependent on the other constructs assessed within a given measure. For example, Rotter's (1967) scale assumes P2T as an unidimensional construct, yet empirical factor analysis evidence indicates up to four factors (Hunt et al., 1983; Wright \& Tedeschi, 1975) while our qualitative analysis suggested five themes. Consequently, if one calculates a single score, these dimensions remain unaccounted within the nomological net. By contrast, the group of scales developed by McKnight et al. (2002) appears to work well as a nomological network. Our content analysis categorised their scales as measuring themes of human nature $(\mathrm{HN})$ and general trust (G). Conceptually these scales are also closely aligned with the trust antecedent model (Mayer et al., 1995) via their reference to competence, reliability and integrity (which we 
grouped within $\mathrm{HN}$ ). As separate scales and with evidence of factorial validity, the McKnight scales could be usefully employed to assess a dispositional tendency of these distinct elements, as well as a more general stance towards trusting. Such multidimensional conception of P2T allows better modeling between human nature beliefs and general tendency to trust, including their relationship with matching beliefs about a specific trustee's trustworthiness. Here Moody, Galletta, and Lowry (2014) offer an excellent example of the nomological connections that can be established using a multidimensional operationalisation of P2T, in this case, using the McKnight et al. scales.

\section{Methodological and conceptual issues in P2T scales}

As with other self-report measures, P2T scales can be subject to systematic methodological bias from the use of common methods (Podsakoff, MacKenzie, Lee, \& Podsakoff, 2003). Such bias can impact on reliability, validity and generalisability. While the emphasis on method variance has drawn attention to the possibility of bias in surveys, what is of more significant interest is how individual variables are affected, and why. Such attention may reveal 'the limits of what people can and cannot self-report accurately', and 'what can and cannot be concluded from data collected using particular designs and methods' (Brannick, Chan, Conway, Lance, \& Spector, 2010, p. 417). In this way, bias raises additional questions about the role of context as an influence on how variables work in the field. McLeary and Cruise (2012) provide evidence for such contextual differences. They used Huff and Kelley's (2003) measure and demonstrated P2T measurement invariance across some, but not all, of the same sector organisations in their study. While measurement error could explain such findings, it nevertheless raises concerns as to why P2T does not generalise well across different organisations, even when of the same type. One possibility could be that it is an artefact of the specific P2T measure used, with different dimensions and items more salient in one context compared to another. The separation of 'hidden' 
subdimensions within unidimensional scales raises awareness and provides an impetus for testing differential effects and contextual interactions, which to date has not been a concern of trust research involving P2T. There are several sources of bias in P2T scales that are worthy of further consideration, next.

\section{Item wording}

A significant source of bias in trust scales is item wording, which occurs in three distinct ways. First, the inclusion of the term 'trust' can be a source of bias, with Cummings and Bromiley (1996) arguing for restraint in its use in measures. Further, Dietz and Den Hartog (2006) contend that the emotive nature of whether one trusts others may distort responses when the word 'trust' is used. While the word 'trust' is included in several of our reviewed scales (see Table 5), it has typically not been acknowledged or explored in studies' methodological discussions. Further, its inclusion may inflate the internal consistency of P2T scales, contributing to an artificial increase in intercorrelations the more frequently the term is used relative to the length of the scale.

Ambiguously-worded items are a second limiting factor that should ideally be omitted from scales to reduce the effects of scale inflation in subsequent empirical analysis and so avoid adding unnecessary further bias (Podsakoff et al., 2003). Ambiguity in P2T scales can arise from multi-referent wording; for example: 'It is easy for me to trust a person/thing' (Lee \& Turban, 2001). While such wording does not appear to be widespread among P2T scales, it can have a more significant impact in short scales. In the preceding example, the ambiguity regarding the object of trust can reduce discriminating power (Broen, 1960), increasing response latency, response acquiescence, item difficulty and the level of nonrespondents (Goldberg, 1963). Consequently, ambiguous items impact on the type of response elicited, and also limit subsequent interpretability. 
A final, and long-standing concern in psychometrics, arises from the conceptual and methodological problems of negatively worded items (Cordery \& Sevastos, 1993). Previous P2T factor analyses have confirmed this (e.g., Ashleigh et al., 2012; Hunt et al., 1983). Further, it may be simplistic and erroneous to assume that negatively worded items are synonymous with distrust (Ferres, Connell, \& Travaglione, 2004), yet this approach appears to have been adopted by some developers in their operationalisation of propensity to trust as distinct from propensity to distrust (e.g., Huff \& Kelley, 2005). Conversely, Dietz and Den Hartog (2006) argue that rather than tapping into low trust, negatively worded items relate to distrust. A further argument supporting Dietz and Den Hartog is that if one were to write items that measure propensity to distrust (P2D), an operationalisation without recourse to negatives would be challenging to achieve, since P2D is by its nature a conceptually negative construct.

Negatively worded items may also relate to constructs that are nomologically connected with P2T and P2D, including cynicism and risk. For example, evidence suggests that cynicism and trust correlate in times of organisational change (Pugh, Skarlicki, \& Passell, 2003), and trust and risk may operate as mirror images of each other (Das \& Teng, 2004). However, until a nomological model specifying the relationships between these similar concepts has been developed, the inclusion of negatively worded cynicism items in P2T scales potentially confounds the measurement of P2T and P2D. Some have advocated excluding negatively worded items from trust measures (Ferres et al., 2004), instead favouring the creation of shorter scales without confounding items. However, it is also conceivable that negatively worded items reflect other constructs, rather than P2D. It is here that a clear conceptual separation of trust and distrust would be helpful, enabling separate treatment of positively and negatively worded items. 


\section{Statistical implications}

Method biases reduce reliability, except in the case of items that include the term 'trust'. The inclusion of 'trust' has the opposite effect making items more similar to each other, artificially increasing item-intercorrelations, thus inflating reliability estimates. Statistical techniques have been used to manage the effects of differences in P2T on other variables (e.g., Ferres et al., 2004). While corrections are available to remedy inflated reliabilities (Pascual-Ferrá \& Beatty, 2015), we are yet to see their explicit use in P2T studies to correct for inflated scale reliabilities. However, when used to control the effect of an independent (predictor) variable, or in mediational and moderator analysis, low reliability can produce complex impacts on the power of statistical analysis, even with further correction (Cohen, Cohen, West, \& Aiken, 2013). Benchmarks for reliability coefficients in research are often misunderstood (Lance, Butts, \& Michels, 2006), leading to the acceptance of low power scales in research. For example, Nunnally and Bernstein (1978) advise on a .8 scale reliability benchmark for basic research rather than the more commonly utilised .7 and argue for an even higher desirable alpha of $>.95$ in applied research contexts where decisions about people are made on the basis a score. However, in practice, attainment of such high levels of reliability is difficult, particularly in studies using multiple scales. A pragmatic response is to reduce the threshold for acceptable scale reliabilities to be lower than the Nunnally and Bernstein gold standard, although this does not necessarily condone the inclusion of measures known to vary widely in their reported reliabilities. Surprisingly, the two most commonly used scales in managerial research, Schoorman et al. (1996) and Rotter (1967) instruments and their variants, frequently result in reliability well below the .7 threshold and vary widely in their ranges. Table 5 highlights the rank order of scales by their reliabilities to aid researchers in selecting more robust scales. 


\section{Meta-analytic considerations}

To our knowledge, there have been few meta-analyses that include P2T in their list of variables. While the use of statistical corrections in meta-analysis is contended to overcome some limitations of low measurement reliability, it may not necessarily be an adequate remedy for low-quality measures. For example, in their meta-analysis, Colquitt et al. (2007) include P2T scales with low and unreported reliabilities. Following good practice conventions, they corrected for attenuation to control for measurement unreliability, reporting both corrected and uncorrected coefficients, plus the standard deviation for corrected coefficients. However, the use of techniques such as imputing mean weighted reliabilities for studies with missing coefficients is itself problematic, as it assumes data are missing at random (Higgins, White, \& Wood, 2008), as well as producing biased estimates (Enders, 2010).

The case for suggesting that reliabilities are not missing at random is that there is some evidence that unreported coefficients may be artefacts of publication pressures, with a tendency of researchers to attempt to obscure lack of significance (Chan \& Altman, 2005). Similarly, the omission of coefficient alpha data might be a strategy that reduces attention to low reliability and underpowered designs. Generally, contemporary editors will favour reporting of relevant benchmarks, and so this is likely to be more of an issue affecting older papers from journals with less robust statistical publication standards. However, under the scenario of nonrandom missingness of reliabilities, the imputation of weighted mean reliability could potentially give a higher estimate than the missing reliability it imputes. As a consequence, subsequent statistical attenuation correction of effect sizes in a meta-analysis using mean imputed values may produce biased effect sizes if they are based on corrections that use over-estimated reliability estimates. 
While low reliability appears to be a more significant concern for earlier studies, there are however also more recent examples of omitted coefficient alpha results in work on P2T (e.g., Chaudhuri, Li, \& Paichayontvijit, 2016; Ishiguro \& Okamoto, 2013; Jansson \& Eriksson, 2015; Wingreen, Mazey, Baglione, \& Storholm, 2018). Reliability concerns are generally widely established in psychology, management science and elsewhere, and so such omissions may reflect editorial policies and practices within research networks. This is an issue that extends beyond P2T measurement and trust research, and as such, requires a continued effort to ensure adequate reporting of scale reliability information in quantitative research.

\section{Scale application considerations}

While our paper aims to provide analysis of P2T scales rather than detailed consideration of studies that have used them, insights about scale application have conceptual relevance. More detailed examination of studies reveals that some fields of study favour different scales (see table 5). The major division here seems to be between online/consumer trust and managerial/organisational applications. Such field-specific applications reflect the dissemination and citation of scales through research networks, with scales trusted more because of familiarity than their quality (for further elaboration of citation behaviours in scientists see also Thornley et al., 2015). Such citation bias has important implications. First, more robust scales are relatively underutilised outside their primary field of application (e.g., McKnight et al., 2002); second, methodological developments and insights gained in different sub-disciplines may gain less traction outside that field, even when such advancements improve measurement. Third, context-dependency of scales and dimensionality imply that measures currently provide an incomplete view of P2T so that research findings derived from using these partial measures of P2T, can at best only offer 
partial insights. For example, distinguishing trusting in people versus trusting institutions in consumer research may provide additional insights into the most effective marketing strategies given an organisation's history and reputation. Finally, perpetuated use of weaker scales in studies in some fields reduces statistical power and undermines the development of theory and evidence in that research subdomain. The implication of a fragmented use of scales creates significant challenges for developing more unified conceptualisations of P2T and in as much as research involving P2T occurs in methodological silos risks incomplete conceptualisation of $\mathrm{P} 2 \mathrm{~T}$ and stagnant theorising that weaken trust research as a whole. Insights from our analysis of scales in terms of their thematic content and overall performance offer a possible solution to this problem.

\section{Conclusions}

Qualitative meta-analysis was used to identify and review 26 measures of P2T used in 179 studies and provided a qualitative mapping of the construct space for each of these scales. While we were surprised both by the number of scales found, and their frequent uncritical acceptance, our subsequent analysis revealed both conceptual and methodological limitations which have consequences for our current understanding of P2T. The number and divergence of scales challenge assertions of a paucity of measures with robust psychometric properties; instead, we found several reliable scales, yet weaker scales tended to have greater application. Mapping the content of scales, we identified coverage of scale content across six themes including beliefs in human nature $(\mathrm{HN})$, cautiousness $(\mathrm{C})$, general trust $(\mathrm{G})$, trust in specific roles $(\mathrm{RE})$, institutional trust $(\mathrm{I})$, and personality attributes $(\mathrm{P})$. Together with factor analytic studies, this points towards an incomplete conceptualisation of P2T as unidimensional.

Scale dimensionality is potentially the biggest threat to existing conceptualisations of P2T. Concerns about the content and dimensionality of P2T are far from trivial matters. From 
a measurement accuracy perspective, prior findings which ignore P2T's multidimensionality potentially confound it with other underexamined antecedent constructs. At best, this creates a limitation, but at worst, it distorts understandings of trust processes in organisational relationships. Second, the presence of multiple dimensions suggests important psychological nuances in the antecedent stage of trust, which are currently neither conceptually nor operationally accounted. P2T may, like trust itself, be a hybrid form construct (McEvily, 2011) based on the output of a variety of other processes, such as risk aversion, optimism bias, scepticism, anxiety or other constituent personality traits all of which are relevant to organisational functioning and trust. Regardless of whether the themes we identified are elements of P2T or other constructs, the validity of P2T measurement is a concern when these elements are confounded within measures and subsequently used without identifying and accounting for their effects. Because many current scales include items that tap these related constructs that are not synonymous with P2T, these scales may produce scores that blend these additional constructs with $\mathrm{P} 2 \mathrm{~T}$. The question of what $\mathrm{P} 2 \mathrm{~T}$ scales assess is rarely considered or clarified and instead depends largely on the measure being used.

One of the most critical insights for us regarding $\mathrm{P} 2 \mathrm{~T}$ is its role as a placeholder or proxy for a series of processes involved in trusting that may be social, cognitive or developmental, but which are not well-defined conceptually. It is beyond this paper to make specific recommendations for what all these processes might be in a nomological net sense. However, in the challenge to more traditional conceptualisations of P2T as dispositional and unidimensional an alternative conceptualisation is possible that can help to drive theorising of P2Ts role in trust at a deeper theoretical level. In light of this review, we revised our original conceptual definition: 
$P 2 T$ is the tendency to become willing to accept risks in relationships under the generalised expectation, shaped by constituent processes of personality, belief and experience, that others can be relied on,

As there was considerable evidence from our own as well as other studies, we devised a separate conceptualisation of $\mathrm{P} 2 \mathrm{D}$ :

$P 2 D$ is the tendency to become unwilling to accept risks in relationships under the generalised expectation, shaped by constituent processes of personality, belief and experience, that others cannot be relied on.

\section{Limitations}

Although we provide a comprehensive identification of P2T scales, our analysis did not consider how individual scales impacted on findings reported, such as on effect sizes, correlations or other indexes of influence. As a result, future studies could examine these influences. Our aim was to examine methodological and thematic aspects of specific P2T scales likely to impact on the interpretation of observed relationships between P2T measures and outcome variables. In that sense the themes produced by our content analysis are not P2T 'factors' in a factor-analytic sense; instead they are a manifestation of item content which may indeed refer to dimensions of P2T or they may alternatively reflect other constructs as we imply in our revised conceptual definition above. While one would not be generalising to populations based on our themes, our findings nevertheless draw attention to the risk of confounding P2T scores with dimensions that are present in P2T scales, but which are usually not accounted for. Although qualitative analysis does not offer the statistical benchmarks or generalisability afforded by a quantitative meta-analysis, they permit a more conceptual exploration of scales and their applications providing conceptual support for subsequent quantitative studies. 


\section{Recommendations \& further work}

In order to advance research further, those studying P2T in action should consider more carefully what 'flavour' of P2T is relevant to their study before selecting suitable scales. The identification, mapping and discussion of existing P2T scales into six thematic areas and our summary tables offer researchers not only insights to discern robust measures but also a taxonomy to aid identification of thematic coverage relevant for their purpose.

We strongly advocate further interrogation of scale dimensionality as P2T effects do not always seem to generalise across organisations of the same type, possibly resulting from dimensionality rendering scales more context-sensitive. Our scale review has highlighted problems in generalisability and interpretation of P2T scales. We advocate that instead of dismissing unusual findings as measurement problems, researchers adopt a more constructive approach by asking under what circumstances a general tendency to trust (and its subdimensions) might become activated in organisational settings. Thus, rather than merely controlling for P2T effects on organisational process studies, complementary control of organisationally- and culturally-relevant variables (such as employee relations, intensity of relations, recent organisational history) may be useful in advancing our understanding of how and why P2T and its subdomains operate in each context, and why they may differ between contexts. A further point relating to conceptual definitions also highlights the need to account for possible generalised constituent processes that give rise to a general willingness to trust. More specifically, where measures tap into these processes, they may reveal dynamic interactions with contextual variables (for example, cynicism in the context of redundancy). Based on our scale evaluation we recommend researchers consider using: a) reliable P2T scales; b) scales whose content does not include the term 'trust'; c) scales which do not confound distrust and trust (achievable through statistically separating positive and negative items); and d) ones that avoid reference to role expectations and institutions. As discussed, 
for conceptual reasons, scales which include role expectations and institution items are potentially problematic. Where such measurement is required, new measures could be developed to focus on a general tendency to trust different roles and institutions.

Alternatively, where such items are already included in a scale that captures these aspects (e.g., Rotter, 1967), removing them or treating them as separate constructs would also be possible strategies. Further consideration of the item space via factor analysis could assist in deciding whether to utilise a 'propensity to distrust' construct in the analysis, which would allow the separate control of variables. Alternatively, where there is neither evidence, nor theoretical requirement for utilising P2D dimensions, negatively worded items should be dropped from the analysis to avoid confounding measurement of P2T.

Alerted by one of our reviewers there may be audience with different types of need. We identify two groups: those focused on researching theoretical aspects of trust and P2T, and a larger group of researchers interested in a broader set of research questions for whom trust may be a secondary concern. The former group may be particularly interested in the possible roles of dimensions in a range of direct or indirect effects (e.g., mediation/moderation) in trust contexts. Furthermore, they will require scales with good psychometric properties that are conceptually strong, appropriate for theory building; the second group will be seek reliable, shorter scales that can be used to control the effects of $\mathrm{P} 2 \mathrm{~T}$ on variables in their research designs.

Our content map highlights that few scales meet all four criteria for P2T scale selection as well as satisfy the needs of different groups of researchers. The four highly reliable short scales produced by McKnight et al. (2002) are noteworthy because they show less evidence of confounding factors, with three subscales also avoiding the term 'trust' (see Table 5). The trusting stance scale is a short, three-item scale for measuring general trust and thus supports designs in which P2T is used to control effects on other variables or in other 
situations when a short measure of P2T is required. An additional feature of McKnight et al's subscales is their alignment with Mayer et al.'s (1995) trustworthiness conceptualisation . Such alignment makes it attractive to trust scholars as using these sub-scales allows operationalisation of theoretically strong and nomologically connected constructs, enhancing study of P2T effects in organisations. Prior work using these scales also has produced variants that mirror the content of the P2T in separate P2D scales (McKnight, Kacmar, \& Choudhury, 2003; Moody et al., 2014). Indeed, the approach of specifying separate variables for each of these theoretically aligned P2T variants in both trust and distrust versions has the potential to disentangle these concepts further empirically.

The main shortcoming of McKnight et al's scales lies in their infrequent use with few published applications. A further limitation is their 'Faith in Human nature - competence' scale, which includes statements about professionals as the trust referent raising issues of contextual relevance. However, the inclusion of this role expectation theme in the competence scale could be highly relevant to organisational contexts in which professionals, as a general category of people, are found. Given the earlier arguments concerning the RE factor, the impact of this expression of RE could easily be controlled within this scale rather than invalidating scores from the competence scale altogether. Instead, it offers scope for further exploration of people's tendency to trust based on generalised beliefs about other people's competence, signalled in this case by their professional status.

The growing multi-referent, multi-level and dynamic study of trust (Fulmer \& Gelfand, 2012, 2013; Gillespie et al., forthcoming) requires measures that can provide the necessary insights into the antecedent processes that activate at different levels, with different referents. Examples of such referents and levels include employee trust in managers, trust between negotiation partners from different organisations, as well as aggregates such as departments, boards, partner organisations with each having distinct accompanying 
situational elements (Goto, 1996) that provide a basis for trusting. Selection of appropriate P2T scales and other antecedents should, therefore, be guided by a consideration of scale content and its predicted relationship with the context in which they are used. Where there is an absence of appropriate scales, one solution may be to devise new scales in response, as seen in the growing trend for context-dependent models of trust, including context-adapted P2T scales (e.g., Jarvenpaa et al., 1998; van der Werff \& Buckley, 2014), multi-dimensional scales (e.g.Ashleigh et al., 2012) and domain-specific scales (Wong \& Williams, 2016). While new scales risk adding to the proliferation problem in trust research, a parallel effort to drive theoretical development underpinning measures should involve researchers adopting a more critical stance to scale selection and development and the retirement of conceptually and methodologically redundant measures.

A final area for critical examination and refinement of P2T theory and measurement lies in studying variability in person-centred antecedents of trust, and how such diversity influences trust in organisations. To date, there has been little attention to how situational, and more general dimensions of P2T interact. Considerations of P2T's nomological network and its antecedent and parallel constituents may provide the necessary conceptual starting point for disentangling these aspects. Such work could provide the nuanced insights necessary to understand better how trust operates in different contexts and to explain why P2T plays a significant role in some organisational contexts, but not others. More research is also needed to address the different impacts such dimensions might have on the competing psychological processes driving trusting. We have identified the need to tighten conceptual definitions of P2T, taking account of the underlying processes influencing people's tendency to trust. Discerning the complex pathways operating in trust situations and help progress trust research in future, would provide a more solid bedrock for improved theorising and the advancement of research across different fields. 


\section{References}

Ale, B. J. (2009). Risk: an introduction: the concepts of risk, danger and chance: Routledge. Ashleigh, M. J., Higgs, M., \& Dulewicz, V. (2012). A new propensity to trust scale and its relationship with individual well-being: implications for HRM policies and practices. Human Resource Management Journal, 22(4), 360-376.

Blau, P. M. (1964). Justice in social exchange. Sociological Inquiry, 34(2), 193-206.

Boon, S. D., \& Holmes, J. G. (1991). The dynamics of interpersonal trust: Resolving uncertainty in the face of risk. Cooperation and prosocial behavior, 190-211.

Brannick, M. T., Chan, D., Conway, J. M., Lance, C. E., \& Spector, P. E. (2010). What is method variance and how can we cope with it? A panel discussion. Organizational Research Methods, 13(3), 407-420.

Broen, W. E. (1960). Ambiguity and discriminating power in personality inventories. Journal of Consulting Psychology, 24(2), 174-179 .

Chan, A.-W., \& Altman, D. G. (2005). Identifying outcome reporting bias in randomised trials on PubMed: review of publications and survey of authors. Bmj, 330(7494), 753.

Chaudhuri, A., Li, Y., \& Paichayontvijit, T. (2016). What's in a frame? Goal framing, trust and reciprocity. Journal of Economic Psychology, 57, 117-135.

Chen, Y., \& Barnes, S. (2007). Initial trust and online buyer behaviour. Industrial Management \&\# 38; Data Systems, 107(1), 21-36.

Cheng, A. S., \& Fleischmann, K. R. (2010). Developing a meta-inventory of human values. Proceedings of the Association for Information Science and Technology, 47(1), 1-10.

Chiu, W. Y. B., \& Ng, F. F. (2015). Enhancement of organizational commitment through propensity to trust. Engineering, Construction and Architectural Management, 22(3), 272-294.

Cohen, J., Cohen, P., West, S. G., \& Aiken, L. S. (2013). Applied multiple regression/correlation analysis for the behavioral sciences. London: Routledge.

Colquitt, J., Scott, B., \& LePine, J. (2007). Trust, trustworthiness, and trust propensity: A meta-analytic test of their unique relationships with risk taking and job performance. Journal of Applied Psychology, 92(4), 909-927.

Colquitt, J. A., \& Rodell, J. B. (2011). Justice, Trust, and Trustworthiness: A Longitudinal Analysis Integrating Three Theoretical Perspectives. The Academy of Management Journal (AMJ), 54(6), 1183-1206.

Connell, J., Ferres, N., \& Travaglione, T. (2003). Engendering trust in manager-subordinate relationships. Personnel Review, 32(5), 569-587.

Cordery, J. L., \& Sevastos, P. P. (1993). Responses to the original and revised job diagnostic survey: Is education a factor in responses to negatively worded items? Journal of Applied Psychology, 78(1), 141-143.

Costa, P. T., \& McCrae, R. R. (1985). Neo PI-R professional manual: Odessa, FL: Psychological assessment resources.

Cronbach, L. J., \& Meehl, P. E. (1955). Construct validity in psychological tests. Psychological bulletin, 52(4), 281-302.

Cummings, L., \& Bromiley, P. (1996). The organizational trust inventory (OTI): Development and validation. In R. Kramer \& T. R. Tyler (Eds.), Trust in organizations: Frontiers of theory and research (pp. 302-330). Thousand Oaks, CA, US: Sage Publications, Inc. 
Das, T., \& Teng, B.-S. (2004). The risk-based view of trust: A conceptual framework. Journal of Business and Psychology, 19(1), 85-116.

Das, T. K., \& Teng, B.-S. (2001). Trust, control, and risk in strategic alliances: An integrated framework. Organization Studies, 22(2), 251-283.

Dietz, G. (2011). Going back to the source: Why do people trust each other? Journal of Trust Research, 1(2), 215-222.

Dietz, G., \& Den Hartog, D. N. (2006). Measuring trust inside organisations. Personnel Review, 35(5), 557 - 588.

Enders, C. K. (2010). Applied Missing Data Analysis. New York: The Guilford Press.

Erikson, E. (1950). Childhood and society. New York: Northern.

Evans, A., \& Revelle, W. (2008). Survey and behavioral measurements of interpersonal trust. Journal of Research in Personality, 42(6), 1585-1593.

Farris, G. F., Senner, E. E., \& Butterfield, D. A. (1973). Trust, culture, and organizational behavior. Industrial Relations: A Journal of Economy and Society, 12(2), 144-157.

Ferguson, A. J., \& Peterson, R. S. (2015). Sinking slowly: Diversity in propensity to trust predicts downward trust spirals in small groups. Journal of Applied Psychology, 100(4), 1012-1024.

Ferres, N., Connell, J., \& Travaglione, A. (2004). Co-worker trust as a social catalyst for constructive employee attitudes. Journal of Managerial Psychology, 19(6), 608-622.

Frazier, M. L., Gooty, J., Little, L. M., \& Nelson, D. L. (2015). Employee attachment: Implications for supervisor trustworthiness and trust. Journal of Business and Psychology, 30(2), 373-386.

Frazier, M. L., Johnson, P. D., \& Fainshmidt, S. (2013). Development and validation of a propensity to trust scale. Journal of Trust Research, 3(2), 76-97.

Fulmer, C. A., \& Gelfand, M. J. (2012). At What Level (and in Whom) We Trust Trust Across Multiple Organizational Levels. Journal of Management, 38(4), 1167-1230.

Fulmer, C. A., \& Gelfand, M. J. (2013). How do I trust thee? Dynamic trust patterns and their individual and social contextual determinants. In K. Sycara, M. Gelfand, \& A. Abbe (Eds.), Models for Intercultural Collaboration and Negotiation (pp. 97-131). Dordrecht: Springer.

Gefen, D. (2000). E-commerce: the role of familiarity and trust. Omega, 28(6), 725-737.

Gill, H., Boies, K., Finegan, J., \& McNally, J. (2005). Antecedents Of Trust: Establishing A Boundary Condition For The Relation Between Propensity To Trust And Intention To Trust. Journal of Business \& Psychology, 19(3), 287-302.

Gillespie, N. (2003, August). Measuring trust in working relationships: the behavioral trust inventory. Paper presented at the Academy of Management Conference, Seattle, WA.

Gillespie, N. (2012). Measuring trust in organizational contexts: an overview of survey-based measures. In F Lyon, G. Möllering, \& M. N. K. Saunders (Eds.), Handbook of research methods on trust (pp. 175-189). Cheltenham UK: Edward Elgar Publishing Limited.

Gillespie, N., Fulmer, A., \& Lewicki, R. (forthcoming). Understanding trust in organizations: a multi-level perspective. New York: Taylor and Francis.

Goldberg, L. R. (1999). A broad-bandwidth, public domain, personality inventory measuring the lower-level facets of several five-factor models. In I. Mervielde, I. Deary, F. De Fruyt, \& F. Ostendorf (Eds.), Personality Psychology in Europe, Vol. 7 (pp. 7-28). Tilburg, The Netherlands: Tilburg University Press.

Goldberg, L. R. (1963). A model of item ambiguity in personality assessment. Educational and Psychological Measurement, 23(3), 467-492.

Goto, S. G. (1996). To trust or not to trust: Situational and dispositional determinants. Social Behavior and Personality, 24(2), 119-131. 
Govier, T. (1994). Is it a jungle out there? Trust, distrust and the construction of social reality. Dialogue, 33(02), 237-252.

Hall, M. A., Camacho, F., Dugan, E., \& Balkrishnan, R. (2002). Trust in the medical profession: conceptual and measurement issues. Health services research, 37(5), 1419-1439.

Hansen, S. D., Dunford, B. B., Alge, B. J., \& Jackson, C. L. (2015). Corporate Social Responsibility, Ethical Leadership, and Trust Propensity: A Multi-Experience Model of Perceived Ethical Climate. Journal of Business Ethics, 137(4), 649-662.

Higgins, J. P., White, I. R., \& Wood, A. M. (2008). Imputation methods for missing outcome data in meta-analysis of clinical trials. Clinical Trials, 5(3), 225-239.

Hsieh, H.-F., \& Shannon, S. E. (2005). Three approaches to qualitative content analysis. Qualitative health research, 15(9), 1277-1288.

Huff, L., \& Kelley, L. (2003). Levels of organizational trust in individualist versus collectivist societies: A seven-nation study. Organization Science, 14(1), 81-90.

Huff, L., \& Kelley, L. (2005). Is collectivism a liability? The impact of culture on organizational trust and customer orientation: a seven-nation study. Journal of Business Research, 58(1), 96-102.

Hunt, R., Kohn, P., \& Mallozzi, C. (1983). Factor analysis of the interpersonal trust scale with a noncollege population. Journal of Personality Assessment, 47(5), 507-508.

Isaeva, N., Bachmann, R., Bristow, A., \& Saunders, M. N. (2015). Why the epistemologies of trust researchers matter. Journal of Trust Research, 5(2), 153-169.

Ishiguro, I., \& Okamoto, Y. (2013). Two ways to overcome social uncertainty in social support networks: A test of the emancipation theory of trust by comparing kin/nonkin relationships. Japanese Psychological Research, 55(1), 1-11.

Jansson, F., \& Eriksson, K. (2015). Cooperation and shared beliefs about trust in the assurance game. PloS one, 10(12), e0144191.

Jarvenpaa, S. L., Knoll, K., \& Leidner, D. E. (1998). Is anybody out there? Antecedents of trust in global virtual teams. Journal of Management Information Systems, 29-64.

Jones, G., \& George, J. (1998). The experience and evolution of trust: Implications for cooperation and teamwork. The Academy Of Management Review, 23(3), 531-546.

Kantsperger, R., \& Kunz, W. H. (2010). Consumer trust in service companies: a multiple mediating analysis. Managing Service Quality: An International Journal, 20(1), 4-25.

Kehr, F., Kowatsch, T., Wentzel, D., \& Fleisch, E. (2015). Blissfully ignorant: the effects of general privacy concerns, general institutional trust, and affect in the privacy calculus. Information Systems Journal, 25(6), 607-635.

Klotz, A. C., Motta Veiga, S. P., Buckley, M. R., \& Gavin, M. B. (2013). The role of trustworthiness in recruitment and selection: A review and guide for future research. Journal of Organizational Behavior, 34(S1), S104-S119.

Kong, D. T. (2018). Trust toward a group of strangers as a function of stereotype-based social identification. Personality and Individual Differences, 120, 265-270.

Kramer, R. M. (1999). Trust and Distrust in Organsiations: Emerging Perspectives, Enduring Questions. Annual Review of Psychology, 50(1), 569-598.

Lagace, R. R., \& Rhoads, G. K. (1988). Evaluation of the MacDonald, Kessel, and Fuller Self-Report Trust Scale. Psychological Reports, 63(3), 961-962.

Lance, C. E., Butts, M. M., \& Michels, L. C. (2006). The sources of four commonly reported cutoff criteria: What did they really say? Organizational Research Methods, 9(2), 202-220.

Landis, J. R., \& Koch, G. G. (1977). The measurement of observer agreement for categorical data. Biometrics 33(1), 159-174. 
Lee, M. K., \& Turban, E. (2001). A trust model for consumer internet shopping. International Journal of electronic commerce, 6(1), 75-91.

Levitt, H. M. (2018). How to conduct a qualitative meta-analysis: Tailoring methods to enhance methodological integrity. Psychotherapy Research, 28(3), 367-378.

Lewis, J. D., \& Weigert, A. (1985). Trust as a social reality. Social forces, 63(4), 967-985.

Li, P. P. (2013). In search of relevant and rigorous measures for trust research: A Yin-Yang approach to institutionalising trust research. Journal of Trust Research, 3(2), 71-75.

MacDonald, A. P., Kessel, V. S., \& Fuller, J. B. (1972). Self-disclosure and two kinds of trust. Psychological Reports, 30(1), 143-148.

Mayer, R. C., Davis, J. H., \& Schoorman, D. F. (1995). An Integrative Model of Organizational Trust. The Academy of Management review, 20(3), 709-734.

McEvily, B. (2011). Reorganizing the boundaries of trust: From discrete alternatives to hybrid forms. Organization Science, 22(5), 1266-1276.

McEvily, B., \& Tortoriello, M. (2011). Measuring trust in organisational research: Review and recommendations. Journal of Trust Research, 1(1), 23-63.

McKnight, D. H., \& Chervany, N. L. (2001). What trust means in e-commerce customer relationships: An interdisciplinary conceptual typology. International journal of electronic commerce, 6(2), 35-59.

McKnight, D. H., Choudhury, V., \& Kacmar, C. (2002). Developing and validating trust measures for e-commerce: An integrative typology. Information systems research, 13(3), 334-359.

McKnight, D. H., Cummings, L. L., \& Chervany, N. L. (1998). Initial Trust Formation in New Organizational Relationships. The Academy of Management review, 23(3), 473490.

McKnight, H., Kacmar, C., \& Choudhury, V. (2003). Whoops... did I use the wrong concept to predict e-commerce trust? Modeling the risk-related effects of trust versus distrust concepts. Proceedings of the 36th Annual Hawaii International Conference on System Sciences. Big Island, Hawaii: University of Hawaii at Manoa.

McLeary, C., \& Cruise, P. (2012). Modeling Organisational Trust: Addressing Challenges of Measurement Invariance. Proceedings of the 11th European Conference on Research Methods, 470-479.

Moody, G. D., Galletta, D. F., \& Lowry, P. B. (2014). When trust and distrust collide online: The engenderment and role of consumer ambivalence in online consumer behavior. Electronic Commerce Research and Applications, 13(4), 266-282.

Mooradian, T., Renzl, B., \& Matzler, K. (2006). Who trusts? Personality, trust and knowledge sharing. Management learning, 37(4), 523-540.

Morse, J. M., Barrett, M., Mayan, M., Olson, K., \& Spiers, J. (2002). Verification strategies for establishing reliability and validity in qualitative research. International journal of qualitative methods, 1(2), 13-22.

Murphy, G. B. (2003). Propensity to trust, purchase experience, and trusting beliefs of unfamiliar e-commerce ventures. New England Journal of Entrepreneurship, 6(2), 5364.

Neuendorf, K. A. (2016). The content analysis guidebook. LA: Sage.

Nienaber, A.-M., Romeike, P. D., Searle, R., \& Schewe, G. (2015). A qualitative metaanalysis of trust in supervisor-subordinate relationships. Journal of Managerial Psychology, 30(5), 507-534.

Nooteboom, B. (2000). Learning by interaction: absorptive capacity, cognitive distance and governance. Journal of management and governance, 4(1-2), 69-92. 
Norheim-Hansen, A. (2015). Are 'green brides' more attractive? An empirical examination of how prospective partners' environmental reputation affects the trust-based mechanism in alliance formation. Journal of Business Ethics, 132(4), 813-830.

Nunnally, J. C., \& Bernstein, I. H. (1978). Psychometric theory. New York: McGraw-Hill.

Oliver, D. (2018, February 20). A matter of trust - doctors, the NHS, patients and the public. Retrieved from https://blogs.bmj.com/bmj/2018/02/20/david-oliver-a-matter-of-trustdoctors-the-nhs-patients-and-the-public/

Oreg, S., Vakola, M., \& Armenakis, A. (2011). Change recipients' reactions to organizational change A 60-year review of quantitative studies. The Journal of Applied Behavioral Science, 47(4), 461-524.

Pascual-Ferrá, P., \& Beatty, M. J. (2015). Correcting internal consistency estimates inflated by correlated item errors. Communication Research Reports, 32(4), 347-352.

Pechar, E., Bernauer, T., \& Mayer, F. (2018). Beyond Political Ideology: The Impact of Attitudes Towards Government and Corporations on Trust in Science. Science Communication, 40(3), 291-313.

Pennanen, K., Tiainen, T., \& Luomala, H. T. (2007). A qualitative exploration of a consumer's value-based e-trust building process: A framework development. Qualitative Market Research: An International Journal, 10(1), 28-47.

Podsakoff, P. M., MacKenzie, S. B., Lee, J. Y., \& Podsakoff, N. P. (2003). Common method biases in behavioral research: a critical review of the literature and recommended remedies. Journal of Applied Psychology, 88(5), 879-903.

Pugh, S. D., Skarlicki, D. P., \& Passell, B. S. (2003). After the fall: Layoff victims' trust and cynicism in re-employment. Journal of Occupational and Organizational Psychology, 76(2), 201-212.

Ridings, C. M., Gefen, D., \& Arinze, B. (2002). Some antecedents and effects of trust in virtual communities. The Journal of Strategic Information Systems, 11(3-4), 271-295.

Rosenberg, M. (1956). Misanthropy and political ideology. American Sociological Review, 690-695.

Rotter, J. (1967). A new scale for the measurement of interpersonal trust. Journal of personality, 35(4), 651-665.

Rotter, J. (1980). Interpersonal trust, trustworthiness, and gullibility. American Psychologist, $35(1), 1-7$.

Rousseau, D. M. (2005). Now let's make multi-level research on trust doable. In F. J.Yammarino \& F. Dansereau (Eds.), Multi-level issues in organizational behavior and processes (pp. 159-166). Oxford: Elsevier.

Rousseau, D. M., Sitkin, S. B., Burt, R. S., \& Camerer, C. (1998). Not so different after all: A cross-discipline view of trust. Academy of management review, 23(3), 393-404.

Saunders, M. N., Dietz, G., \& Thornhill, A. (2014). Trust and distrust: Polar opposites, or independent but co-existing? Human Relations, 67(6), 639-665.

Sayers, A. (2008). Tips and tricks in performing a systematic review. Br J Gen Pract, 58(547), 136-136.

Schoorman, F. D., Mayer, R. C., \& Davis, J. H. (1996, April). Empowerment in veterinary clinics: The role of trust in delegation. Paper presented at the symposium on trust at the 11th Annual Conference, Society for Industrial and Organizational (SIOP), San Diego.

Schoorman, F. D., Mayer, R. C., \& Davis, J. H. (2007). An integrative model of organizational trust: Past, present, and future. Academy of Management Review, 32(2), 344-354.

Schuessler, K. F. (1982). Measuring social life feelings. San Francisco: Jossey-Bass Inc Pub. 
Searle, R., \& Billsberry, J. (2011). The Development and Destruction of Organizational Trust During Recruitment and Selection In R. H. Searle \& D. Skinner (Eds.), Trust and Human Resources Management. (pp. 67-86) Chichester: Edward Elgar.

Searle, R., Weibel, A., \& Den Hartog, D. N. (2011). Employee trust in organizational contexts. In G.P. Hodgkinson \& J. K. Ford (Eds.), International Review of Industrial and Organizational Psychology 2011 (pp.143-191). New York: Wiley.

Stack, L. C. (1978). Trust. In H. London \& J. Exner (Eds.), Dimensions of personality (561597). New York: John Wiley \& Sons.

Thornley, C., Watkinson, A., Nicholas, D., Volentine, R., Jamali, H. R., Herman, E., .. . Tenopir, C. (2015). The role of trust and authority in the citation behaviour of researchers. Information Research, 20(3).

Timulak, L (2013) Qualitative meta-analysis, In U. Flick (2013), The SAGE handbook of qualitative data analysis. London: Sage.

Uslaner, E. M. (2002). The moral foundations of trust. New York: Cambridge University Press.

Valenzuela, S., Park, N., \& Kee, K. F. (2008, April). Lessons from Facebook: The effect of social network sites on college students' social capital. Paper presented at the 9th International Symposium on Online Journalism, University of Texas, Texas, US.

van der Werff, L., \& Buckley, F. (2014). Getting to Know You: A Longitudinal Examination of Trust Cues and Trust Development During Socialization. Journal of Management, 43(3), 742-770.

Wingreen, S. C., Mazey, N. C., Baglione, S. L., \& Storholm, G. R. (2018). Transfer of electronic commerce trust between physical and virtual environments: experimental effects of structural assurance and situational normality. Electronic Commerce Research, 1-33.

Wong, T., \& Williams, M. (2016, November). A Domain-Specific Trust Propensity Scale. Paper presented at the First International Network on Trust (FINT) conference, Dublin.

Wright, T., \& Tedeschi, R. (1975). Factor analysis of the interpersonal trust scale. Journal of Consulting and Clinical Psychology, 43(4), 470-477.

Wrightsman, L. (1964). Measurement of philosophies of human nature. Psychological Reports, 14(3), 743-751.

Yamagishi, T., Kikuchi, M., \& Kosugi, M. (1999). Trust, gullibility, and social intelligence. Asian Journal of Social Psychology, 2(1), 145-161.

Yates, F. J., \& Stone, E. R. (1992). The risk construct. In J. F. Yates (Ed.), Risk-Taking Behavior (pp. 1-25). New York: Wiley.

Zeffane, R. (2015). Trust, personality, risk taking and entrepreneurship: Exploring gender differences among nascent and actual entrepreneurs in the United Arab Emirates. World Journal of Entrepreneurship, Management and Sustainable Development, 11(3), 191-209. 